\title{
Erratum to: Activation of blood coagulation in chronic urticaria: pathophysiological and clinical implications
}

\author{
Marco Cicardi
}

Published online: 22 May 2010

(c) SIMI 2010

Erratum to: Intern Emerg Med (2010) 5:95-96

DOI 10.1007/s11739-010-0373-x

Unfortunately, the title of the article had been given incorrectly. It should read:

Activation of blood coagulation in chronic urticaria: pathophysiological and clinical implications.

The online version of the original article can be found under doi:10.1007/s11739-010-0373-x.

M. Cicardi ( $\square)$

Dipartimento di Scienze Cliniche "Luigi Sacco", Ospedale

Luigi Sacco, Universitá di Milano, Milan, Italy

e-mail: marco.cicardi@unimi.it 